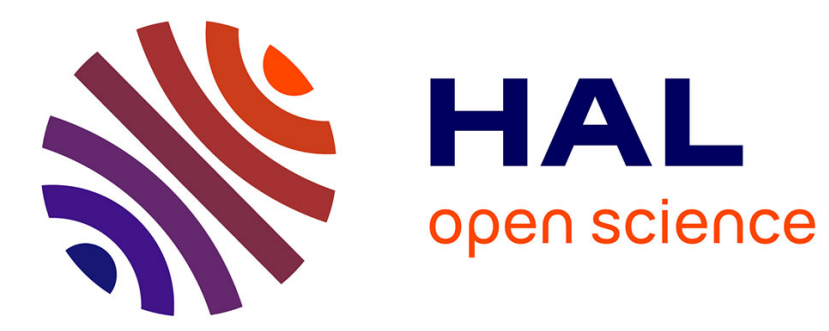

\title{
Flux distribution of the Superphénix start-up core for the validation of neutronic codes
}

\author{
E. Garcia, P. Sciora, T. Kooyman, G. Rimpault, H. Guo, B. Faure
}

\section{To cite this version:}

E. Garcia, P. Sciora, T. Kooyman, G. Rimpault, H. Guo, et al.. Flux distribution of the Superphénix start-up core for the validation of neutronic codes. Annals of Nuclear Energy, 2019, 133, pp.889-899. 10.1016/j.anucene.2019.06.066 . cea-02535326

\section{HAL Id: cea-02535326 https://hal-cea.archives-ouvertes.fr/cea-02535326}

Submitted on 24 Jul 2020

HAL is a multi-disciplinary open access archive for the deposit and dissemination of scientific research documents, whether they are published or not. The documents may come from teaching and research institutions in France or abroad, or from public or private research centers.
L'archive ouverte pluridisciplinaire HAL, est destinée au dépôt et à la diffusion de documents scientifiques de niveau recherche, publiés ou non, émanant des établissements d'enseignement et de recherche français ou étrangers, des laboratoires publics ou privés. 


\title{
Flux distribution in the Superphénix start-up core with APOLLO3
}

\author{
E. Garcia, P. Sciora, T. Kooyman and G. Rimpault \\ Commissariat à l'Energie Atomique, Centre d'Etudes Nucléaires de Cadarache \\ 13108 St. Paul-lez-Durance, France
}

Elias.Yammir.GARCIA-CERVANTES@cea.fr, pierre.sciora@cea.fr, gerald.rimpault@cea.fr

\begin{abstract}
The Superphénix reactor remains the largest Sodium-cooled Fast Reactor ever built in the world and its legacy is a unique source of information for SFRs. At the Superphénix start-up, a series of tests (Transversal Irradiation tests) were devoted to the core flux distribution with measurements in several subassembly positions located from the core center to its periphery. On the other hand, the recent development of neutronic codes has improved accuracy and it is worthwhile to try reproducing these tests. The APOLLO3 code for instance can treat complex geometries without substantial approximations. The Superphénix radial and axial flux profiles are assessed for two Transversal irradiation tests, with a reference Monte Carlo code (TRIPOLI-4) and two deterministic codes, the ERANOS code and its successor the APOLLO-3 code. In a first time, a numerical validation between codes is done to observe the deterministic code bias on the fission rate by comparing the ERANOS and APOLLO-3 evaluations to the TRIPOLI-4 model. Good agreement is seen between codes, and discrepancies between ERANOS and APOLLO-3 remain limited. However, the use of APOLLO-3 eliminates any potential fission rate bias due to the possible compensating errors at the assembly step calculation. An additional survey on the fission rate variations between the JEFF 3.1.1 and the JEFF 3.2 with the same code shows that minor differences are found for the Transversal irradiation tests. It can be concluded that current computational tools are relevant for predicting core flux distribution.
\end{abstract}

KEYWORDS: Superphénix reactor, start-up commissioning tests, APOLLO-3

\section{INTRODUCTION}

The Generation IV International Forum (GIF) is a co-operative international organization that provides the roadmap for the research and development of nuclear reactors by considering its feasibility and competitiveness. One of the prototypes to be developed is the Sodium-cooled Fast Reactor (SFR) which already offers considerable experimental feedback. For instance, the French research program offers three experimental facilities: Rapsodie, Phénix and Superphénix.

Superphénix, being the successor of Rapsodie and Phénix, included the experimental feedback gained operating these two reactors. The aim of Superphénix was to serve as the first large SFR prototype and to demonstrate its industrial feasibility to eventually achieve commercial SFR deployment for electricity production. Interest in SFR has been revived with the development of SFRs projects, such as the Advanced Sodium Technological Reactor for Industrial Demonstrator (ASTRID) in France or the commissioning of the $\mathrm{BN}-800$ reactor in Russia. 
During the Superphénix start-up, specific experimental programs were devoted to assess the various safety criteria of the core. Namely the control rod worth and the flux distribution were addressed in different tests throughout the commissioning phase (Gourdon, Mesnage, Voitellier, \& Suescun, 1990).

In this paper, the Superphénix flux distribution is analyzed and compared to experimental measurements. This examination uses the latest neutronic platforms for a given nuclear data evaluation, taking as reference calculation the stochastic code TRIPOLI-4, which is then compared to the ERANOS and APOLLO-3 deterministic codes. The purpose of the use of multiple codes is to quantify the bias between each other and to determine if modeling limitations restrain the Superphénix tests analysis.

Chapter 2 provides a brief description of the core characteristics and the tests under analysis while chapter 3 provides an explanation of the methodology used and the calculation schemes associated with each of the codes. Chapter 4 compares the experimental results and the numerical results obtained for each of the code used in this work. Finally, the conclusions of this paper are presented in chapter 5.

\section{START-UP CORE: TRANSVERSAL IRRADIATION TESTS}

The Superphénix start-up core (CMP, Cœur de Montée en Puissance) reached criticality the 3th October of 1985. It contained a total of 358 fuel subassemblies distributed in two concentric cores with different fuel enrichments (see Figure 1) (Flamenbaum, de Wouters, Le Bourhis, Newton, \& Vambenepe, 1990). Fertile blankets were loaded above and below the core fissile column, 221 fertile subassemblies were loaded around the core as a radial blanket. The height of the radial blanket fertile zone was equivalent to the combined heights of the axial blankets and fissile column.

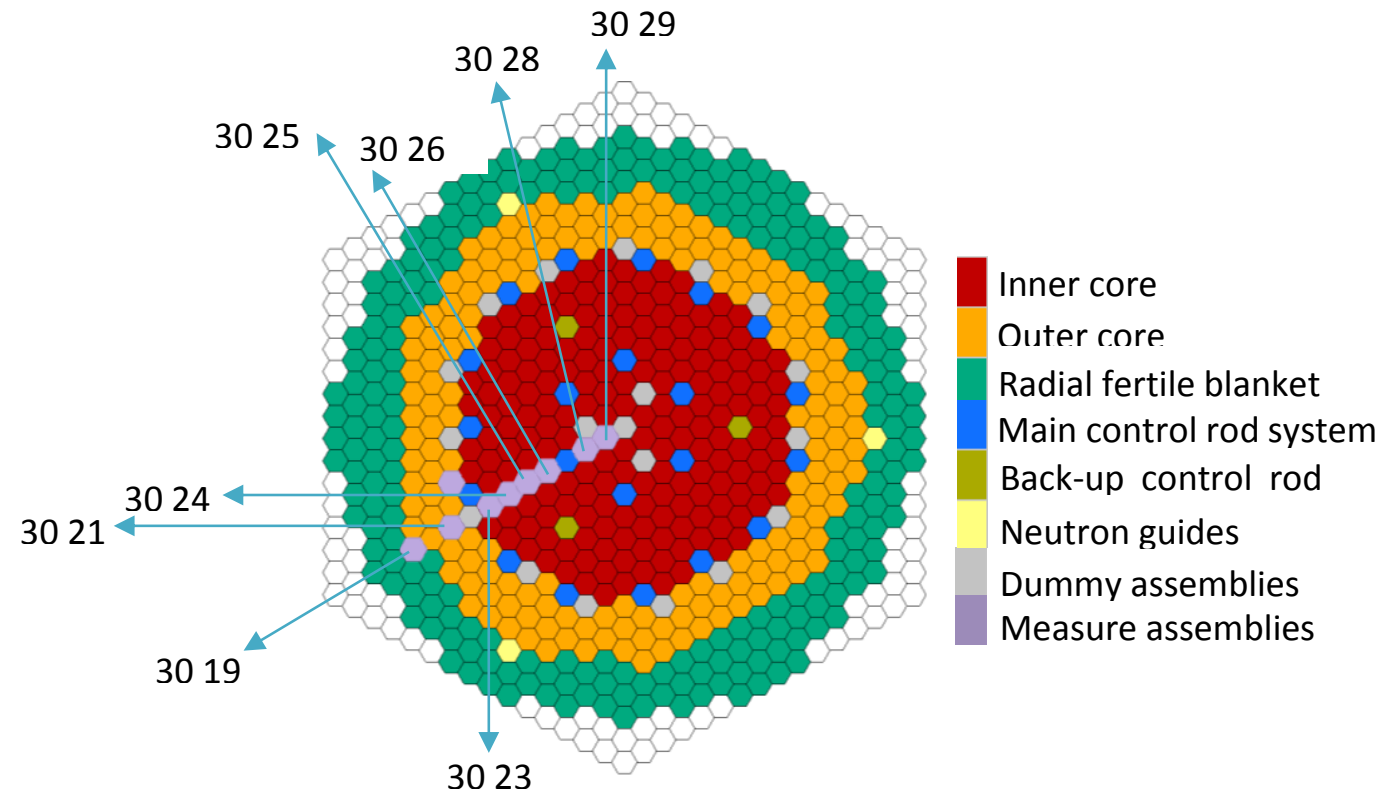

Figure 1. Core map layout for Transversal Irradiation test and measurement subassemblies positions.

The main control rod system (SCP, Système de Commande Principale) was composed by 21 subassemblies composed of 31 absorber pins with $90 \%{ }^{10} \mathrm{~B}$ enriched boron carbide. The SCP was divided in two curtains; an inner curtain with 6 absorber subassemblies and an outer one with 15 absorber subassemblies at the interface of the inner and outer core. A more precise description of 
the different kinds of subassemblies can be found in the reference (Garcia, Sciora, \& Rimpault, 2019).

As the CMP presented fresh fuel conditions, 18 dummy assemblies were loaded near the SCP subassemblies to limit the reactivity excess at the core start-up. The dummy assemblies present a highly heterogeneous geometry with steel pins on a lattice arrangement.

The transversal irradiation tests were performed to provide a validation of the core calculation methods and of the design performance assessments. The determination of these reaction rate distributions provided information on axial and radial profiles.

The large size core of the Superphénix compared to the neutron mean-free-path implies large spatial decoupling and higher sensitivity of the flux to a local perturbation. Thus, the control rod interaction effects are mainly influenced by the physical properties of this large size core (Flamenbaum, Zaetta, Martini, Michenot, Newton, \& Sztark, 1990). For this reason, the flux distribution was experimentally analyzed in two tests, the Transversal Irradiation 1 (T1) and the Transversal Irradiation 2 (T2) with different rods positions, to obtain the sensitivity to this parameter and its influence on the local peak power. Both tests consisted in loading specific measurement subassemblies in particular positions of the core, as shown in Figure 1 (Cabrillat \& Martini, 1990). These measurement assemblies contained a capsule device at its center, in which different detectors could be axially loaded during core operation. Figure 2 shows a cross section of the measurement subassembly designed for these tests. Different detectors were loaded in the capsule of the measurement assembly, namely ${ }^{235} \mathrm{U},{ }^{238} \mathrm{U}$, and ${ }^{239} \mathrm{Pu}$ foils for fission reaction and gold, sodium and nickel foils for activation reaction.

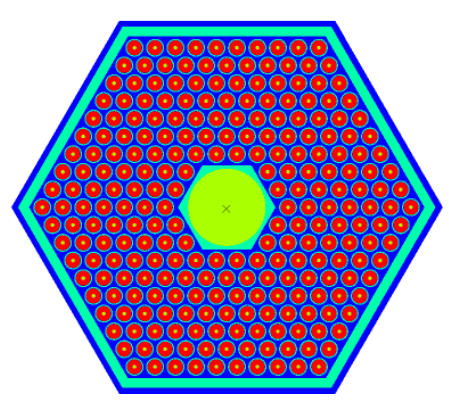

Figure 2. Cross section of measurement assemblies in Transverse Irradiation tests

Radially from the center, these measurements concerned six sub-assembly positions of the inner core (30 29 to 3023 ), one position of the outer core (30 21) and one position of the radial fertile blanket (30 19) as seen in Figure 1.

These tests were performed under low power conditions (3MWth) in isothermal state at $180^{\circ} \mathrm{C}$. The main difference between the $\mathrm{T} 1$ and the $\mathrm{T} 2$ is the axial position of the control rods. In the $\mathrm{T} 1$ irradiation tests, all the rods of the SCP curtains are inserted at the same height, while in the T2 irradiation, a flux imbalance is created by extracting the inner rods and further inserting the outer rods of the SCP curtain. These tests permitted to observe the impact on the fission rate for different neutron flux conditions. Figure 3 provides a schematic of these tests. 

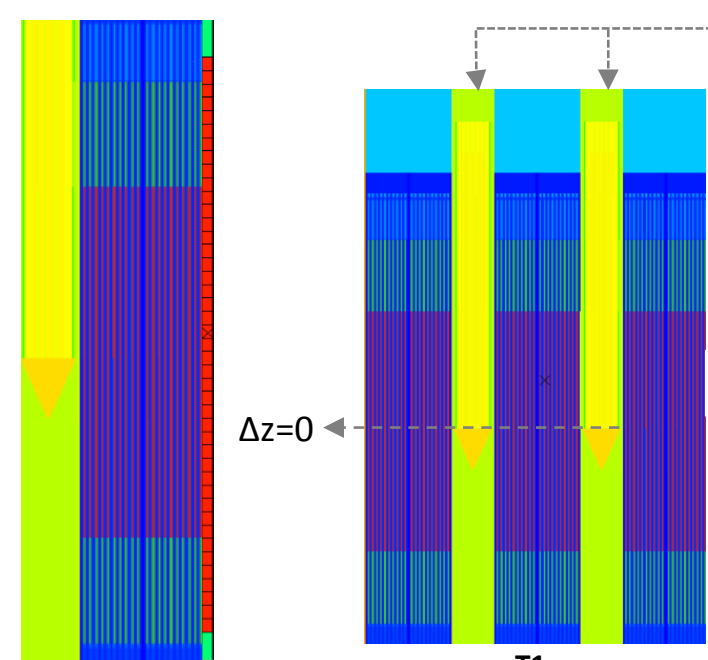

T1

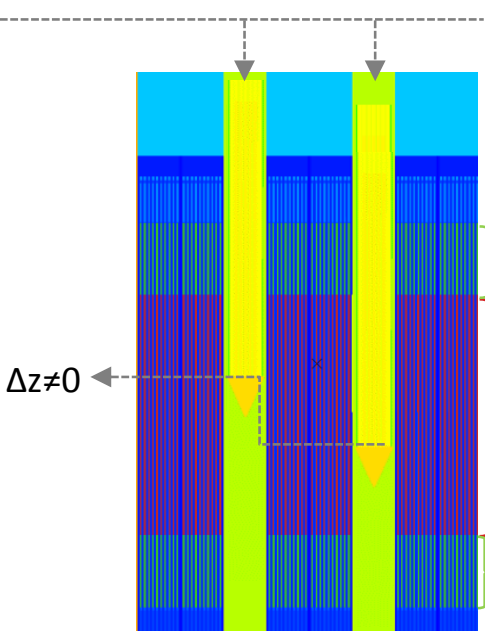

T2

Control rods

Upper axial blanket

Fissile core

Bottom axial blanket

Axial capsule

Figure 3. Axial layout of Irradiation test and control rod axial position.

\section{ANALYSIS}

\subsection{Stochastic analysis}

The stochastic analysis is done with the TRIPOLI-4 code (Brun, et al., 2015), which relies on the Monte Carlo method. The Monte Carlo calculations are used here as the reference calculations as their approximations are limited. The Superphénix geometry model used in the present paper has been already validated in (Garcia, Sciora, \& Rimpault, 2019). For the current simulations, runs were performed with 25,000 neutrons and 5100 iterations, of which 5000 were active iterations. These simulations have been executed with the use of probability tables in the unresolved resonance region. These run parameters were used to ensure a standard deviation of less than $10 \mathrm{pcm}$ on reactivity and a standard deviation of less than $3 \%$ on the fission rate values.

Regardless of the accurate evaluations with TRIPOLI-4, a considerable amount of computing resources are required to perform these evaluations which leads to large calculation times for this model. For this reason, the use of deterministic method is recommended, since their use could simplify these evaluations without increasing the error in the physical parameters of interest as it will be shown latter.

\subsection{Deterministic analyses}

The deterministic analysis is performed with ERANOS (Rimpault, et al., 2002) and APOLLO-3 (Schneider, Dolci, Gabriel, Palau, Guillo, \& Pothet, 2016) codes. In deterministic codes, the analysis is performed in two steps: an assembly calculation for effective cross section production and a core 
evaluation that uses the produced cross sections at the assembly calculation level. In this section the modeling differences between the ERANOS code and the new APOLLO-3 code are given.

\subsubsection{Effective cross section production}

The effective cross section production for ERANOS is performed with ECCO (European Cell Code), which is based on the subgroup method combined with a transport calculation with an approximate collision probability method to deal with slowing-down and self-shielding (Rimpault G. , 1995). The assembly calculation considers a 1968 energy mesh, and for fuel and fertile assemblies is done with a heterogeneous geometry description, whereas the structure assemblies (such as dummies, control rods and reflectors) use a homogeneous geometry description. Nevertheless, the use of a heterogeneity correction for the control rod assemblies is done to take into account the spatial effects in the core calculations as shown in reference (Tommasi, Czernecki, \& Rimpault, 2002) .

One of the main limitations in ECCO is the modeling of complex geometries. For instance the modeling of the measurement assembly (see Figure 1) cannot be exactly defined as it is shown in Figure 4. Hence, the whole capsule measurement is homogeneously treated (in geometry and composition) by placing large-pin structures in the fuel assembly lattice. Furthermore, the treatment of the heterogeneity is using the simplified multicell approach.

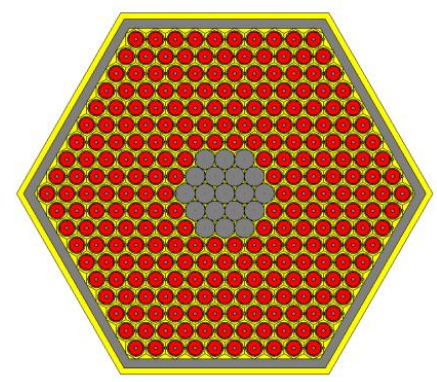

Figure 4. Measurement assembly modeling in ECCO.

The effective cross section production with APOLLO3 is performed with the Two/Three Dimensional Transport (TDT) solver with a 1968 energy mesh. The multigroup flux calculation is done with the method of characteristics (MOC-TDT) and the self-shielding is evaluated with the collision probability method (TDT-MOC) with the Tone formalism (Mao \& Zmijarevic, 2017).

Two assembly calculation approaches are presented: the cluster and the 2D/1D method recently validated in reference (Faure, Archier, Vidal, \& Buiron, 2018). The effective cross section production for fuel and axial fertile regions was produced with the 2D/1D method, while structures and control rods cross sections were produced using the cluster approach, which intends to provide representative flux spectra for these assemblies. Thus, at the homogenization step, the effective cross-sections of each subassembly are individually treated for its input at the core step calculation. For the control rods, the absorber media is independently treated the homogenization step and it is separated from the structure and coolant sections of the subassembly as it was validated in reference (Guo, et al., 2019). 
Contrary to the ERANOS description, the APOLLO-3 can treat the measurement assembly geometry more precisely. However both codes include approximations with ECCO using the multicell approach and APOLLO-3 the Tone formalism rather than the more accurate sub-group method. As for the control rods, the assembly is treated with the cluster approach and at the homogenization step, the detector and the assembly are separately homogenized to be individually treated at the core evaluation. Figure 5 shows the schematics of the 2D/1D method and the cluster geometries.

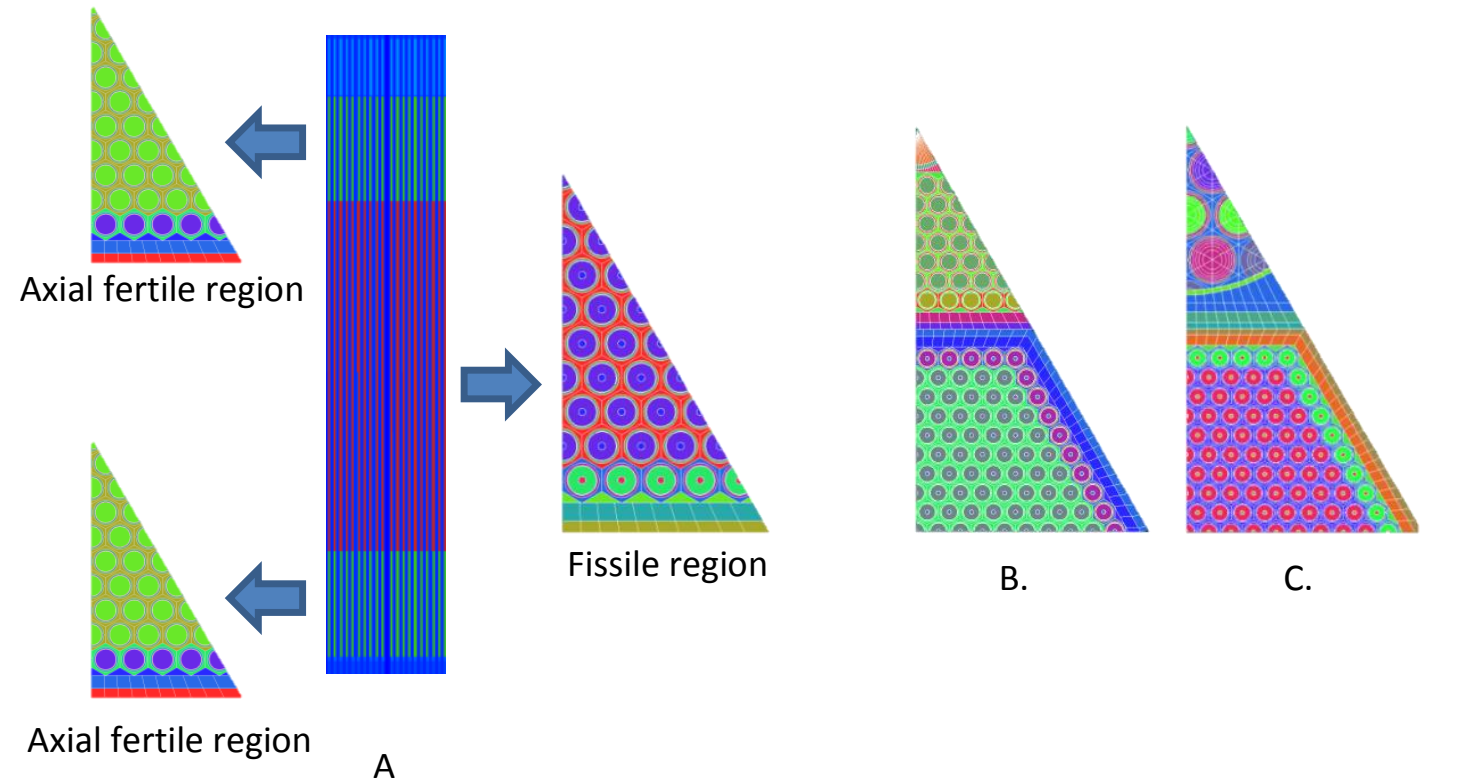

Figure 5. A. 2D/1D representation and the different mediums in the assembly and B. Measurement cluster and C. Control rod cluster.

The core evaluation with ERANOS is performed with the VARIANT-TGV full transport solver. This solver uses a variational nodal method associated to a PN method based on the development of the angular flux according to bases of polynomials (Legendre polynomials in space and spherical harmonics in angle). One of the drawbacks of the VARIANT TGV solver is that it is only capable of handling hexagonal meshes without sub-geometries, which imposes a full homogenization of assemblies at the core evaluation and consequently flux reconstruction procedures have to be implemented during the post-processing stage. This prevents a full heterogeneous treatment of the measurement assemblies at the core calculation level.

The core evaluation in APOLLO3 is done with the MINARET core solver, which is a transport discrete ordinates (Sn) solver. The MINARET also contains several features to speed up the resolution of the transport equation: MPI parallel computation (parallelism on angular directions), DSA method and Chebyshev acceleration. Unlike the ERANOS core solver, the MINARET core solver has the capability to deal with sub-geometries, which is the reason why particular regions have been treated independently during the assembly step. As such, a higher accuracy is expected with the use of the APOLLO3 calculation code.

Taking advantage of this, the control rods are defined with a semi-heterogeneous description as in reference (Guo, et al., 2019). In the core calculation the absorber medium of the control rods are independently treated by individually describing these media geometry and using the corresponding effective cross section calculated in the lattice step. It hence does not require the use of any 
equivalence reactivity method as in ERANOS which preserves reactivity but does not allow accurate flux distribution.

As the control rods, the detectors are also defined independently at the core calculation, while the rest of the subassembly is homogenized and defined as a regular hexagon. As a consequence, the flux on the detector can be obtained without any reconstruction method as it is done in former solvers.

C.
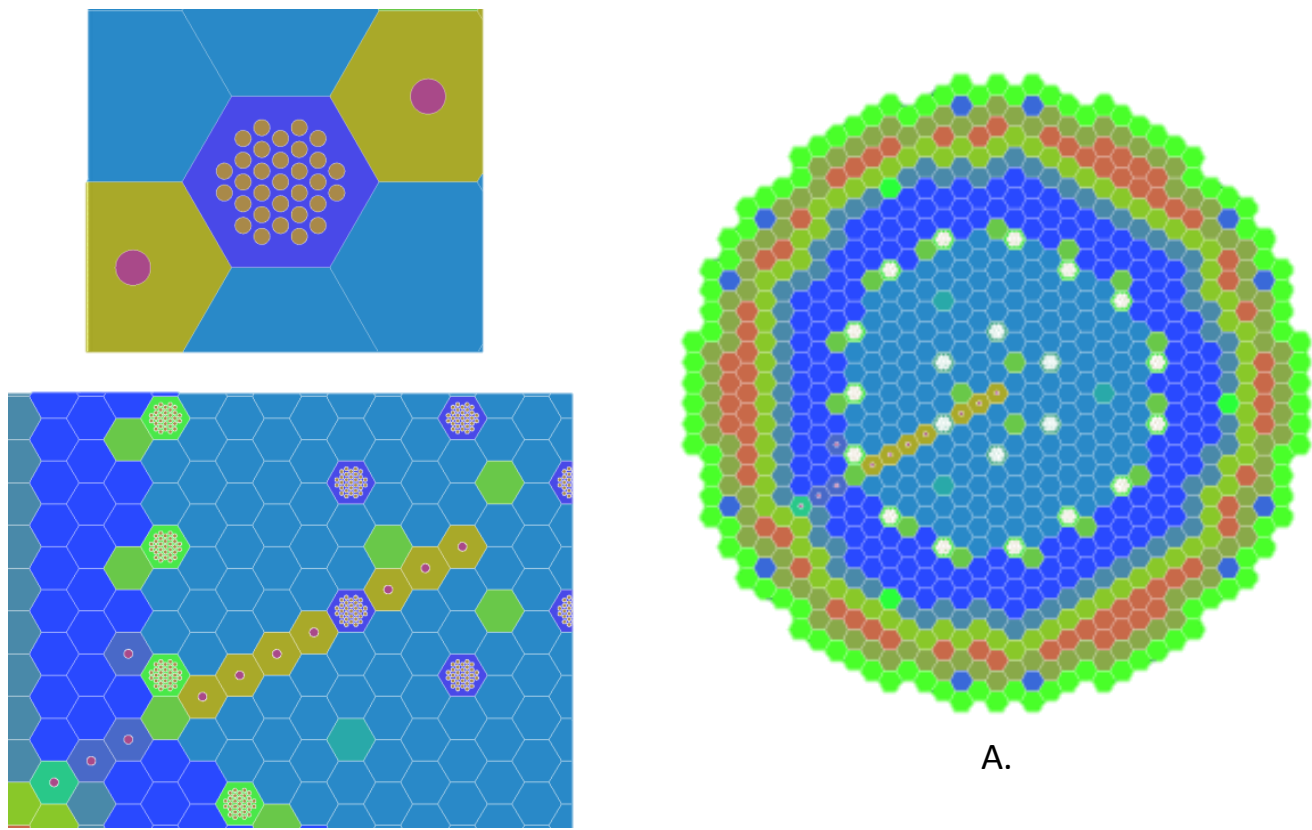

A.

B.

Figure 6. A. MINARET view of the core layout, B. Measurement assemblies row definition in the core solver and C. Control rod assembly definition in the core solver

Figure 6 shows the schematics of the MINARET core solver for the core map layout (A.), the control rod and detectors semi-heterogeneous geometry description at the core calculation (B.) and the radial column loaded in the Superphénix for the Transversal Irradiation tests (C.).

\section{RESULTS}

The flux distribution evaluations are presented in this section. For the Transversal Irradiation T1, the ${ }^{239} \mathrm{Pu}$ fission rate at the mid-height of the core is assessed to observe the radial flux distribution. Besides, the axial fission rate profile of the subassembly 3026 is analyzed. This subassembly has been selected because it is next to the control rod 3027 (see Figure 1) and its flux distribution presents an important gradient contrary to other fuel subassemblies far from the rods. This is a challenge for the deterministic codes capability to accurately reproduce the flux distribution along the sub-assembly because of their homogenization methods and plate flux hypothesis for the core calculation. Analogously, for the Transversal Irradiation 2 the ${ }^{235} \mathrm{U}$ fission rate is assessed for the radial flux profile and the same subassembly position $(3026)$ for the axial fission rate distribution.

The assessments of these tests are first conducted through a numerical validation between codes, namely by using a complete TRIPOLI-4 model as a reference and comparing it to the APOLLO-3 and 
ERANOS evaluations. Subsequently, experimental validation is performed by comparing the measurement to each evaluation.

\subsection{Numerical validation}

At first, a numerical validation is performed to check codes consistency. A TRIPOLI-4 model, validated in (Garcia, Sciora, \& Rimpault, 2019), is taken to be the reference evaluation and it is compared against the deterministic evaluations of ERANOS and APOLLO-3. Figure 7 presents the assemblies loaded in the radial column with the nature of each to serve as guide in the following evaluations. The both black subassemblies of the Figure 7 are not used in this interpretation: the 3020 did not contain any detector, the 30-24 presented non useful measurements for the loaded detector's nature, and for this reason it is not taken into account in the experimental validation as it was done in the previous interpretations (Czernecki, 1998).

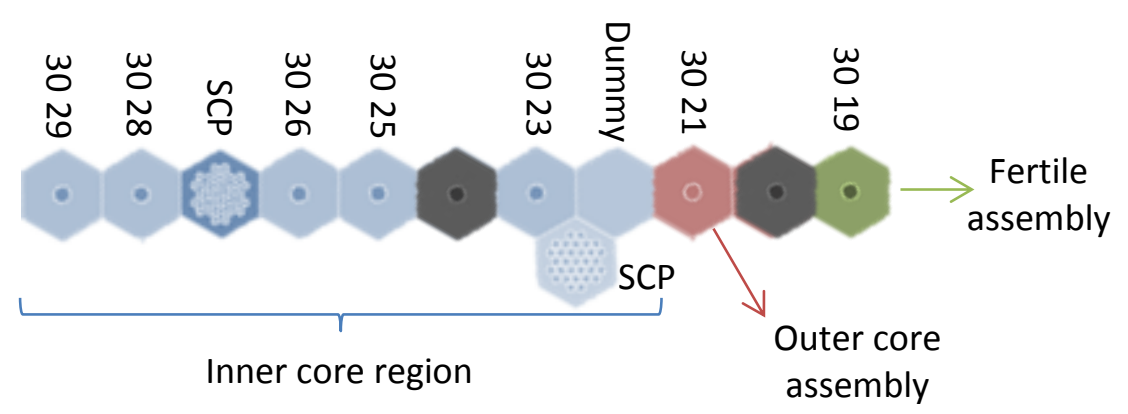

Figure 7. Irradiation column description in T1 and T2

In Table 1, the T1 core's radial profile discrepancies between TRIPOLI-4 and deterministic codes are shown for the ${ }^{239} \mathrm{Pu}$ fission rate at mid-height of the active core, for which in general, a good agreement is observed. The largest discrepancy for both codes is observed at the 3021 position, which is next to a dummy assembly and near a control rod assembly. The discrepancies between APOLLO-3 and TRIPOLI-4 are slightly lower than those observed between ERANOS and TRIPOLI-4, with a maximal difference between discrepancies of about $1 \%$ (position 3021 ).

Table 1. Radial ${ }^{239} \mathrm{Pu}$ fission rate distribution discrepancy (in \%) between TRIPOLI-4 and APOLLO-3 (AP3-T4) and TRIPOLI4 and ERANOS (ERN-T4) for the T1 at the mid-height of the active core.

\begin{tabular}{|c|c|c|c|c|c|c|c|}
\hline T1 & 3029 & 3028 & 3026 & 3025 & 3023 & 3021 & 3019 \\
\hline ERN-T4 & 0.00 & 2.45 & 1.04 & -0.49 & -0.48 & 2.56 & 0.52 \\
\hline AP3-T4 & 0.00 & 1.20 & 1.10 & 1.21 & -0.38 & 1.47 & 0.33 \\
\hline
\end{tabular}

The core's radial profile discrepancies for the T2 are shown in Table 2. As in the previous case, a good agreement between codes is observed, with a consistent overall trend. This time the ERANOS largest discrepancy is identified in the 3021 position, whereas the largest APOLLO-3 discrepancy is observed in 3023 position. Once more, the APOLLO-3 code has slightly lower discrepancies than ERANOS when comparing to TRIPOLI-4, except for positions 3028 and 3023. 
Table 2. Radial ${ }^{239} \mathrm{Pu}$ fission rate distribution discrepancy (in \%) between TRIPOLI-4 and APOLLO-3 (AP3-T4) and TRIPOLI4 and ERANOS (ERN-T4) for the T2 at the mid-height of the active core.

\begin{tabular}{|c|c|c|c|c|c|c|c|}
\hline T2 & 3029 & 3028 & 3026 & 3025 & 3023 & 3021 & 3019 \\
\hline ERN-T4 & 0.00 & 0.24 & 1.62 & 0.60 & -1.47 & 2.95 & -1.15 \\
\hline AP3-T4 & 0.00 & -0.27 & 0.72 & 0.35 & -1.68 & 0.67 & -0.75 \\
\hline
\end{tabular}

The axial fission rate discrepancies between TRIPOLI-4 and deterministic codes APOLLO-3 and ERANOS for assembly 3026 is provided in Table 3 . There is a clear trend with both deterministic codes to produce an underestimation from the bottom to the mid-height of the core and to an overestimation from this point until the top of the core. For both deterministic codes the discrepancies increase at the bottom or at the top of the core, this means in the fertile area region.

Table 3. Axial ${ }^{239} \mathrm{Pu}$ fission rate distribution discrepancy (in \%) between TRIPOLI-4 and APOLLO-3 (AP3-T4) and TRIPOLI-4 and ERANOS (ERN-T4) for the T1 and the 3026 assembly position.

\begin{tabular}{|c|c|c|c|c|}
\hline Region & $\mathrm{Z}[\mathrm{cm}]$ & AP3-T4 & ERN-T4 & ERN-AP3 \\
\hline Bottom & 58 & -2.15 & -2.58 & -0.43 \\
\cline { 2 - 5 } fertile & 66 & -1.59 & -2.18 & -0.59 \\
\cline { 2 - 5 } blanket & 74 & -1.40 & -2.46 & -1.06 \\
\hline \multirow{4}{*}{ Active } & 82 & -2.99 & -3.61 & -0.62 \\
\cline { 2 - 5 } core & 90 & -1.71 & -1.95 & -0.25 \\
\cline { 2 - 5 } & 98 & -1.22 & -1.81 & -0.58 \\
\cline { 2 - 5 } & 106 & 0.34 & -0.67 & -1.00 \\
\cline { 2 - 5 } & 114 & 0.20 & -0.98 & -1.18 \\
\cline { 2 - 5 } & 122 & 0.27 & -0.72 & -0.99 \\
\cline { 2 - 5 } & 130 & 0.00 & 0.00 & 0.00 \\
\cline { 2 - 5 } & 138 & 1.00 & 0.03 & -0.97 \\
\cline { 2 - 5 } & 146 & 1.44 & 0.57 & -0.87 \\
\cline { 2 - 5 } & 154 & 1.71 & 0.99 & -0.73 \\
\cline { 2 - 5 } & 170 & 1.04 & 0.40 & -0.63 \\
\cline { 2 - 5 } & 178 & 1.80 & 1.22 & -0.57 \\
\hline Upper & 186 & 0.07 & -0.63 & -0.70 \\
\cline { 2 - 5 } fertile & 192 & 1.38 & 0.17 & -0.65 \\
\cline { 2 - 5 } blanket & 200 & 2.64 & 2.19 & -0.72 \\
\hline
\end{tabular}

For the same position, the 3026 assembly, the same assessment is done for the T2 test as it is shown in Table 4. The same trend observed before is seen with APOLLO-3: an underestimation from the bottom to the mid-height of the core and overestimation from this point until the top of the core. However, this time the ERANOS shows a different trend, with a general overestimation along the axial distribution except for a couple of positions near the mid-height of the core. 
Table 4. Axial ${ }^{239} \mathrm{Pu}$ fission rate distribution discrepancy (in \%) between TRIPOLI-4 and APOLLO-3 (AP3-T4) and TRIPOLI-4 and ERANOS (ERN-T4) for the T2 and the 3026 assembly position.

\begin{tabular}{|c|c|c|c|c|}
\hline Region & $Z[\mathrm{~cm}]$ & AP3-T4 & ERN-T4 & ERN-AP3 \\
\hline Bottom & 51 & 0.09 & 1.17 & 1.09 \\
\cline { 2 - 5 } fertile & 63 & -0.70 & 1.64 & 2.34 \\
\cline { 2 - 5 } blanket & 75 & -0.81 & 1.29 & 2.10 \\
\hline & 87 & -0.78 & 0.51 & 1.28 \\
\cline { 2 - 5 } & 99 & -0.59 & -0.11 & 0.48 \\
\cline { 2 - 5 } Active & 111 & -0.86 & -0.85 & 0.01 \\
\cline { 2 - 5 } core & 123 & 0.00 & 0.00 & 0.00 \\
\cline { 2 - 5 } & 135 & 0.86 & 0.95 & 0.09 \\
\cline { 2 - 5 } & 147 & 3.71 & 3.39 & -0.32 \\
\cline { 2 - 5 } & 159 & 3.40 & 2.63 & -0.77 \\
\cline { 2 - 5 } & 171 & 4.01 & 3.88 & -0.13 \\
\hline Upper & 183 & 4.44 & 6.03 & 1.59 \\
\cline { 2 - 5 } fertile & 195 & 5.55 & 5.92 & 0.37 \\
\cline { 2 - 5 } blanket & 207 & 4.53 & 1.80 & -2.73 \\
\hline
\end{tabular}

Overall, the discrepancies of APOLLO-3 and ERANOS compared to TRIPOLI-4 remain very close to each other, with minor discrepancies for the radial and axial profiles. The main differences are observed in the upper and lower fertile regions.

\subsection{Nuclear data survey}

Additionally, a nuclear data survey was done to address the fission rate change between the JEFF 3.1.1 and JEFF 3.2 nuclear data libraries. To avoid statistical uncertainty of the TRIPOLI-4 code, the APOLLO-3 code was selected to perform this task. In Table 5 the radial fission rate differences due to the nuclear data change between JEFF 3.1.1 and JEFF 3.2 is given for the T1 at mid-height of the active core. A very good agreement is seen between these evaluations with minor differences between each other (largest remains $>1 \%$ ). This assessment was also completed for the axial distribution of the 3026 sub-assembly, and as in radial profile, discrepancies were found to be below $1 \%$.

Table 5. Radial ${ }^{239} \mathrm{Pu}$ fission rate distribution discrepancy (in \%) between JEFF 3.2 and JEFF 3.1.1 (J32-J311) and the use of the APOLLO-3 for the T1 at the mid-height of the active core for.

\begin{tabular}{|c|c|c|c|c|c|c|c|}
\hline $\mathrm{T} 1$ & 3029 & 3028 & 3026 & 3025 & 3023 & 3021 & 3019 \\
\hline $\mathrm{J} 32-\mathrm{J} 311$ & 0.00 & -0.86 & 0.21 & 0.34 & 0.02 & -0.18 & -0.47 \\
\hline
\end{tabular}

\subsection{Experimental validation}

Uncertainties in measurements depend on the detector nature, the "real" position of the detector and the control rod axial position in the core. For these tests, the uncertainty of measurements is $2.4 \%$ for ${ }^{239} \mathrm{Pu}$ detectors and $2.2 \%$ for ${ }^{235} \mathrm{U}$ detectors at mid-height of the core. But for measurements near the axial or radial blankets, the measurement uncertainty might increase up to $4 \%$ and $5 \%$ respectively for ${ }^{239} \mathrm{Pu}$ and ${ }^{235} \mathrm{U}$ detectors. 
Additionally, the SCP axial position presents an uncertainty, and consequently the flux distribution can be perturbed. This can be extrapolated to the fission rate uncertainty of the tests by comparing the fission rate variation with TRIPOLI-4 for the possible positions of the SCP, taking the upper and lower uncertainty boundaries. For the T1 test, the fission rate uncertainty due to the control rod position is evaluated to be $3 \%$ at the mid height of the core, whereas for the T2 test, it is evaluated to be $3.5 \%$.

\section{Transversal Irradiation 1}

As it was shown in reference (Garcia, Sciora, \& Rimpault, 2019), a Superphénix TRIPOLI-4 model has been experimentally validated against a set of start-up tests at the commissioning phase. As an example, the TRIPOLI-4 axial fission rate is given for the 3026 sub-assembly position.

The axial fission rate of subassembly 3026 with TRIPOLI- 4 is presented in Figure 8 . The fission rate is well evaluated along the subassembly with discrepancies dispersed between $2.5 \%$ and $-3 \%$. Most of the discrepancies are between $-1 \%$ and $1 \%$ and only for 6 positions the discrepancies exceed this range, which are mostly found either on the axial fertile region or close to the axial fertile region.

Despite the fact that the TRIPOLI-4 is in very good agreement with the experiment, considerable computing resources are required to perform this calculation. For this reason, the use of deterministic methods is an alternative option to perform this analysis, which requires less time and which accuracy is acceptable enough to reproduce these tests. In the following, the T1 is analyzed with the ERANOS and APOLLO-3 code.

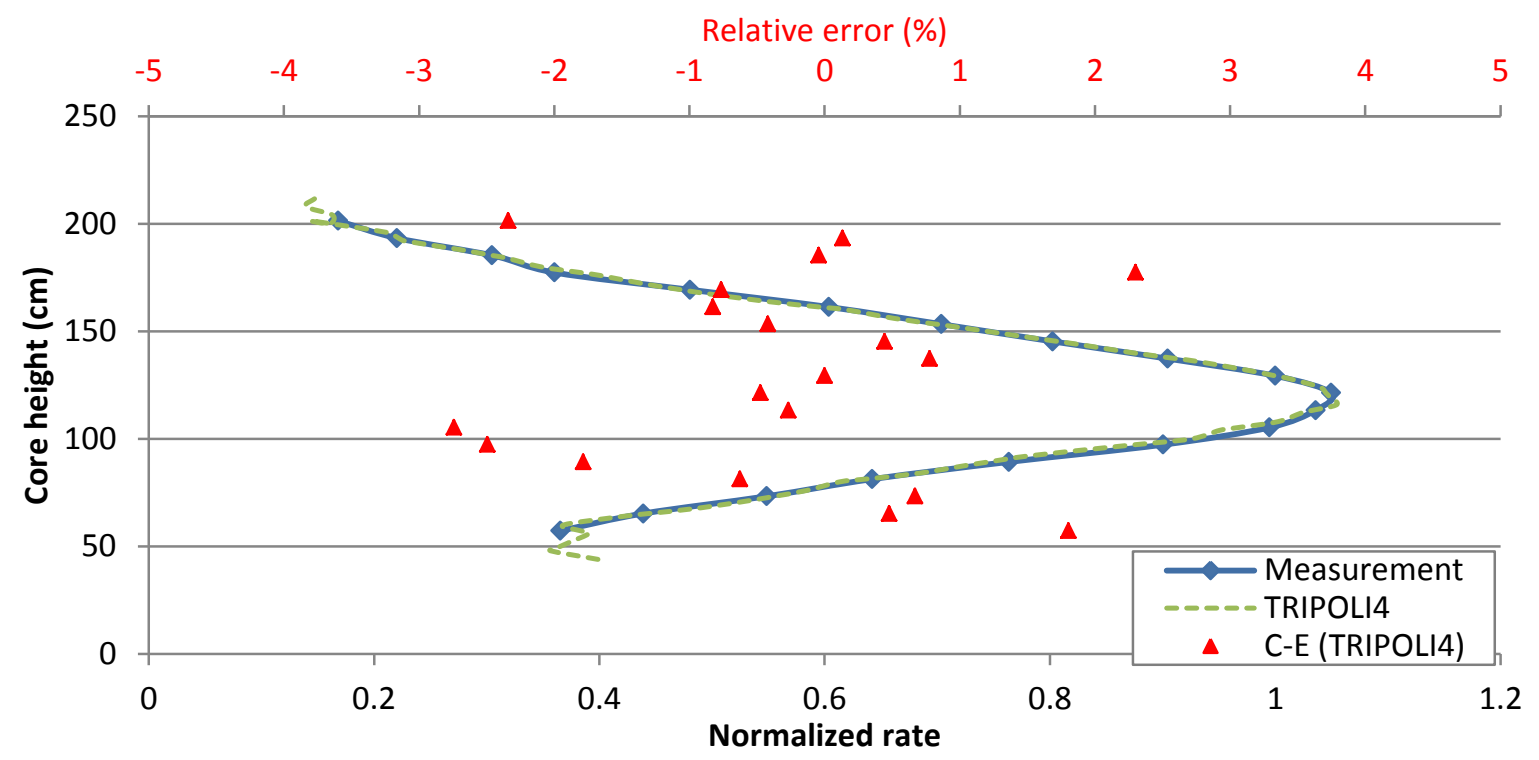

Figure 8. Measurement and TRIPOLI-4 axial ${ }^{239}$ Pu fission rate for position 3026.

Results of the fission rate with ERANOS are given in Figures 9 and 10, respectively for radial and axial profile. Compared to the measurements in Figure 9, the ERANOS calculations show a good agreement in the radial flux distribution, the largest discrepancy is $2.6 \%$ and it is found to be in the position 3028 , next to a control rod subassembly. The same discrepancy is found in the position 30 21 , next to the dummy assembly and in the vicinity of a control rod. These discrepancies are consistent with the numerical verification of the previous section. 
The discrepancy in position 3028 can be related to the heterogeneous correction applied to the control rods, and an analogous effect is present in position 3021 , in which the dummy heterogeneous geometry might increase the fission rate discrepancies because of its vicinity with the analyzed sub-assembly.

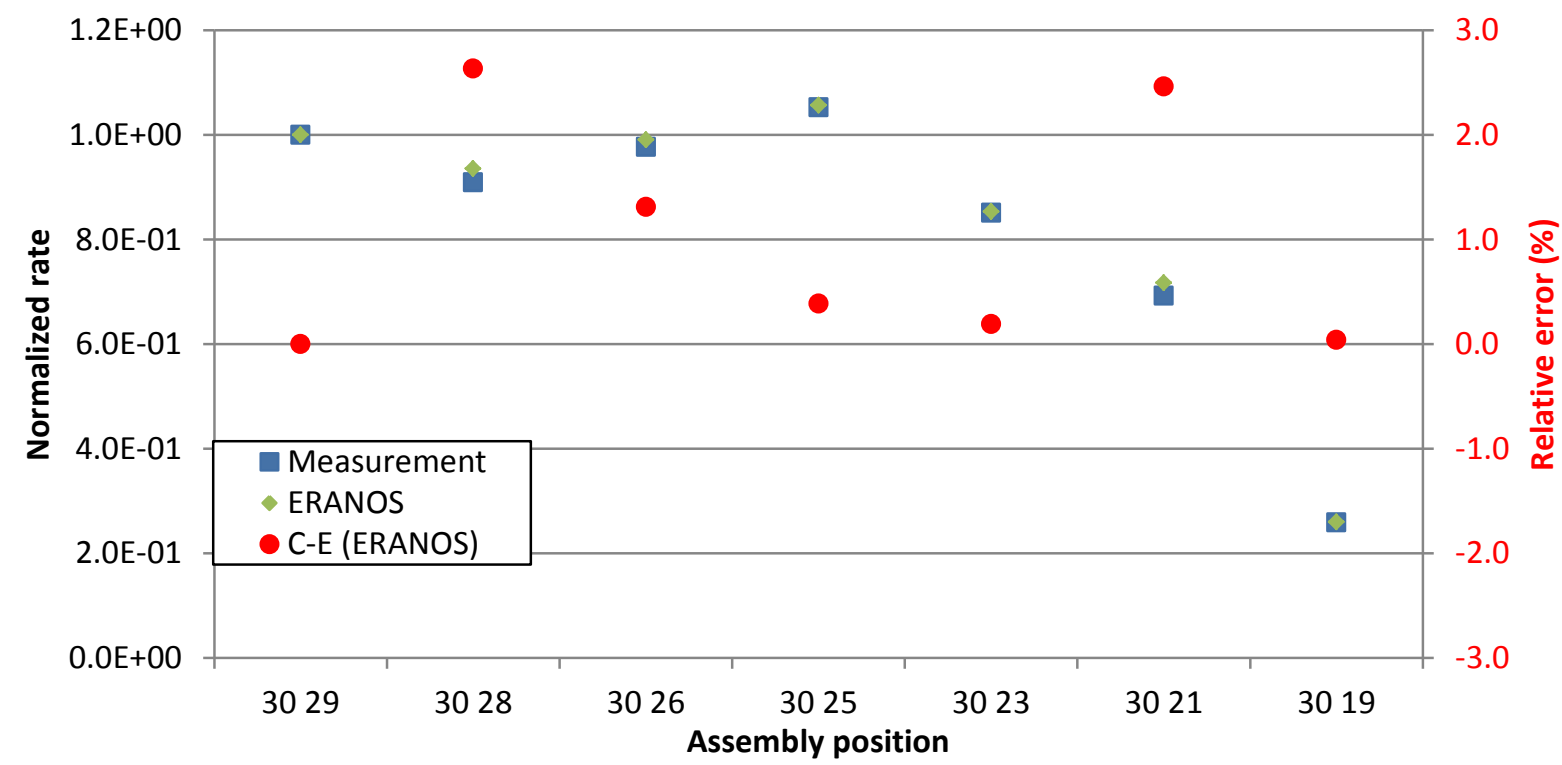

Figure 9. Measurement and ERANOS ${ }^{239} \mathrm{Pu}$ fission rate at mid-height of the core.

Figure 10 presents the axial fission rate profile of the 3026 position assembly and its comparison to measurements. The bottom region tends to present larger errors than the top or the center of the core, for a discrepancy range between $-4.3 \%$ and $2 \%$. The same behavior was seen for the numerical validation with TRIPOLI-4, in which a fission rate underestimation was observed from the bottom to the mid-height of the core and an overestimation from this latter to the top of the core.

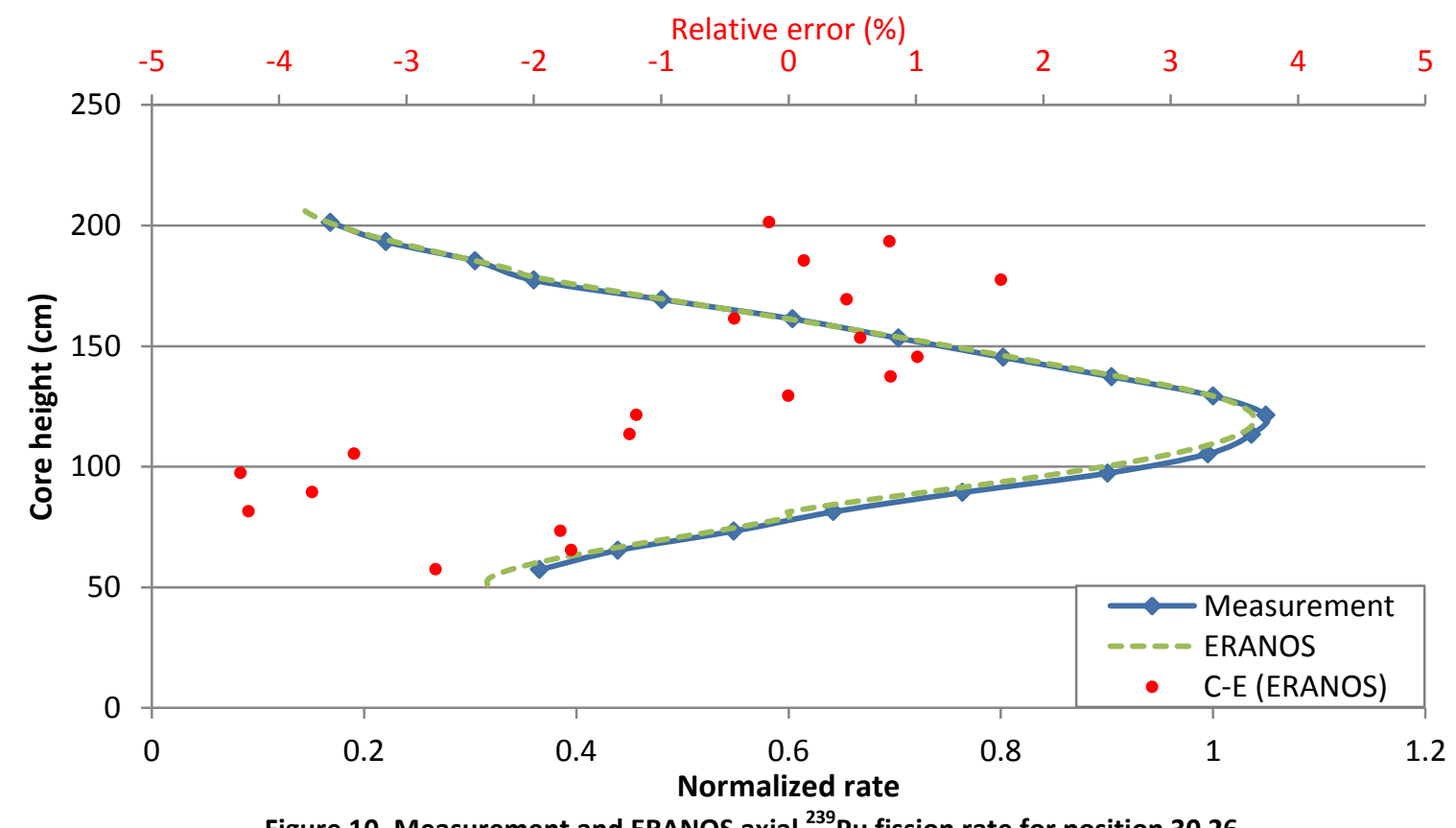

Figure 10. Measurement and ERANOS axial ${ }^{239}$ Pu fission rate for position 3026. 
The radial flux distribution profile with APOLLO-3 is shown in Figure 11 and is in good agreement with the experimental measures. The radial flux distribution with APOLLO3, compared to experimental evaluations is also in good agreement. The range of discrepancies remains between a \pm $2 \%$ difference with the tests, which is about $1 \%$ more than TRIPOLI-4.

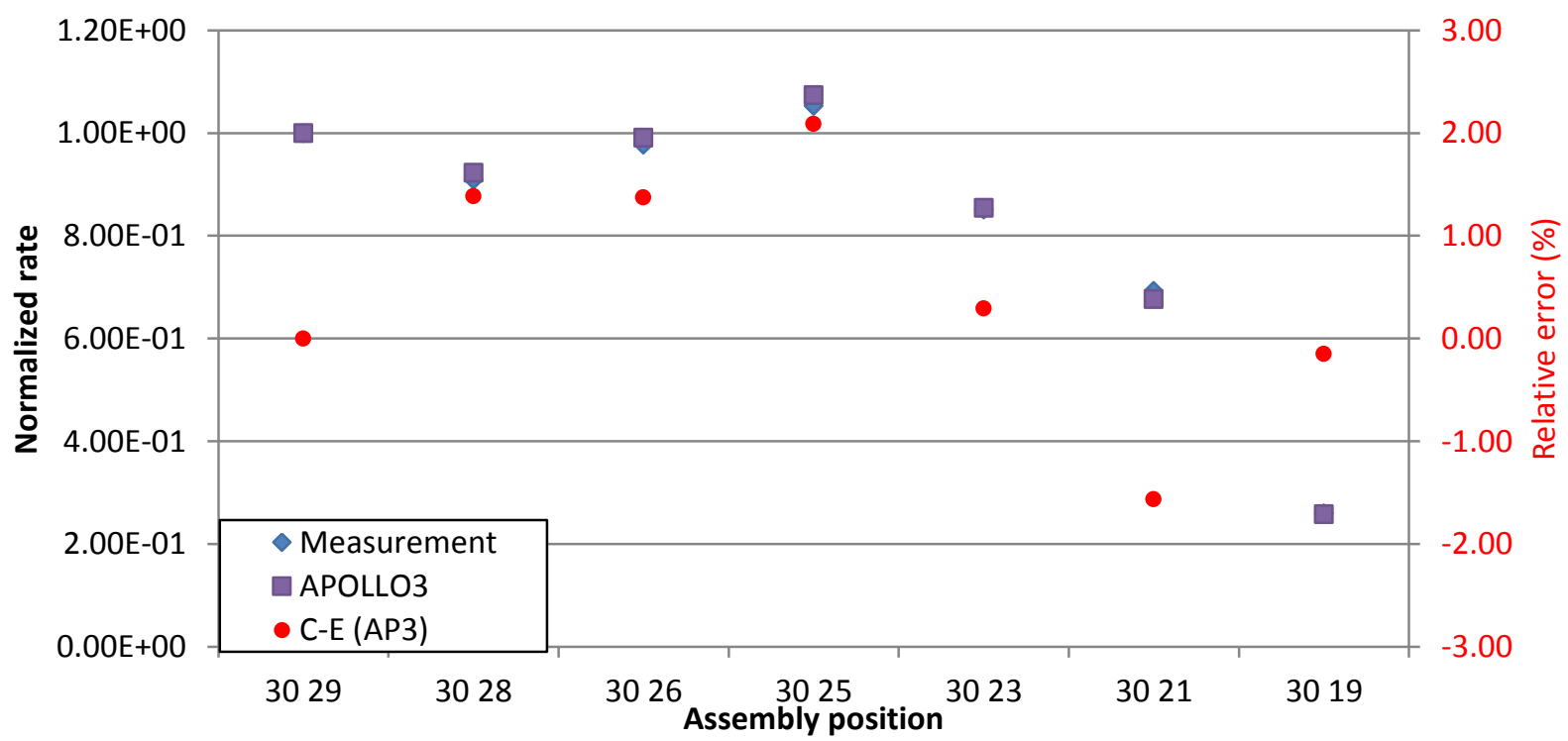

Figure 11. Measurement and APOLLO3 ${ }^{239} \mathrm{Pu}$ fission rate at mid-height of the core.

Figure 12 shows the experimental measurements and the evaluations with APOLLO- 3 which show a good agreement for the axial fission rate with discrepancies within $-4 \%$ and $2.4 \%$. As with ERANOS evaluations, a fission rate underestimation is seen from the bottom to the mid height of the core; however the discrepancies are marginally reduced with APOLLO-3.

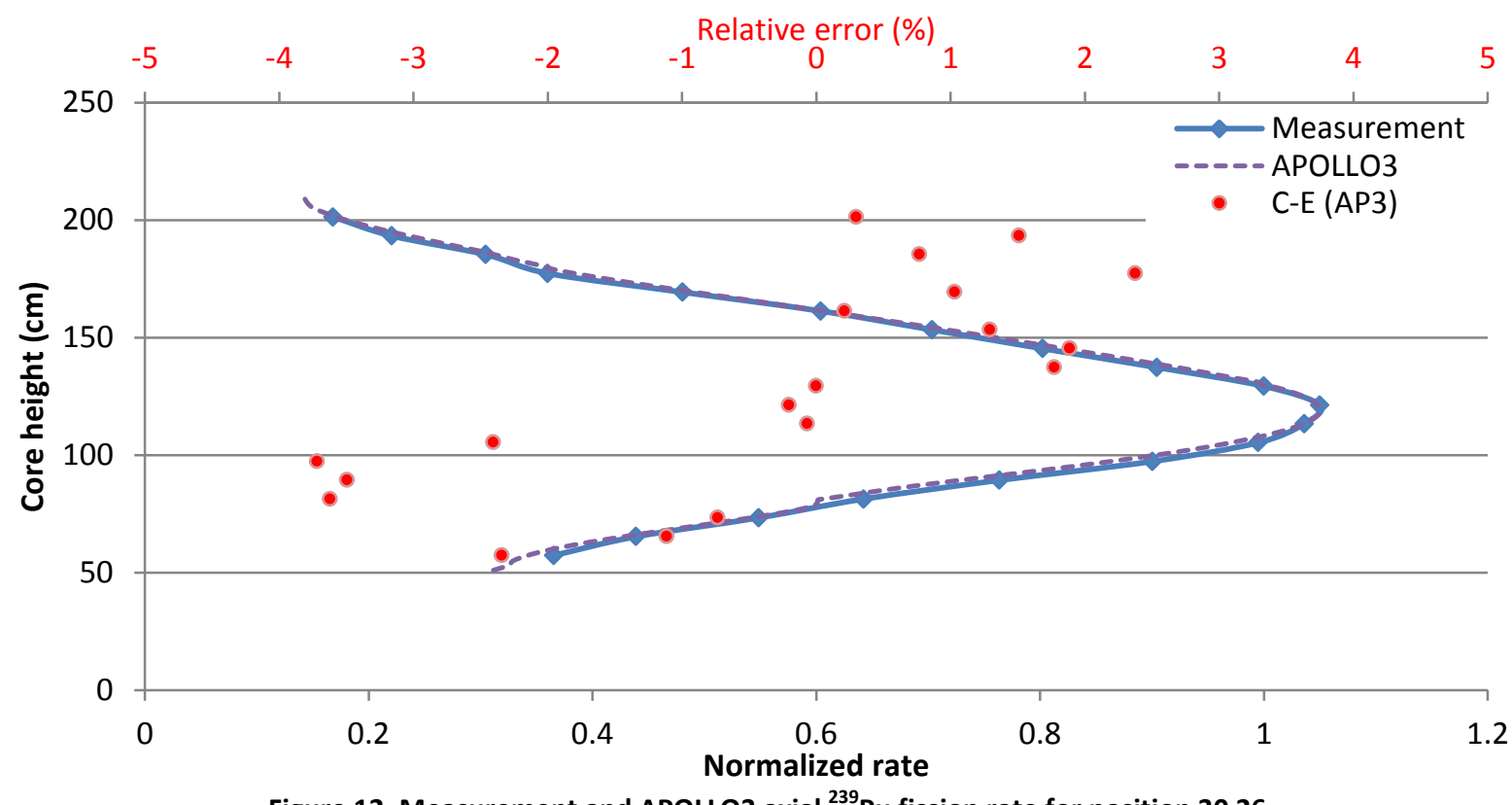

Figure 12. Measurement and APOLLO3 axial ${ }^{239} \mathrm{Pu}$ fission rate for position 3026 


\section{Transversal Irradiation 2}

The results concerning the axial fission rate in the Transversal irradiation 2 with TRIPOLI-4 are shown in Figure 14 for axial distribution in the core. The axial fission rate of position 3026 is in good agreement with measurements. Discrepancies between this evaluation and the measurements are found to be within a $-2.3 \%$ to $2 \%$ error. In general the fission rate is well reproduced either radially or axially for this test with TRIPOLI-4.

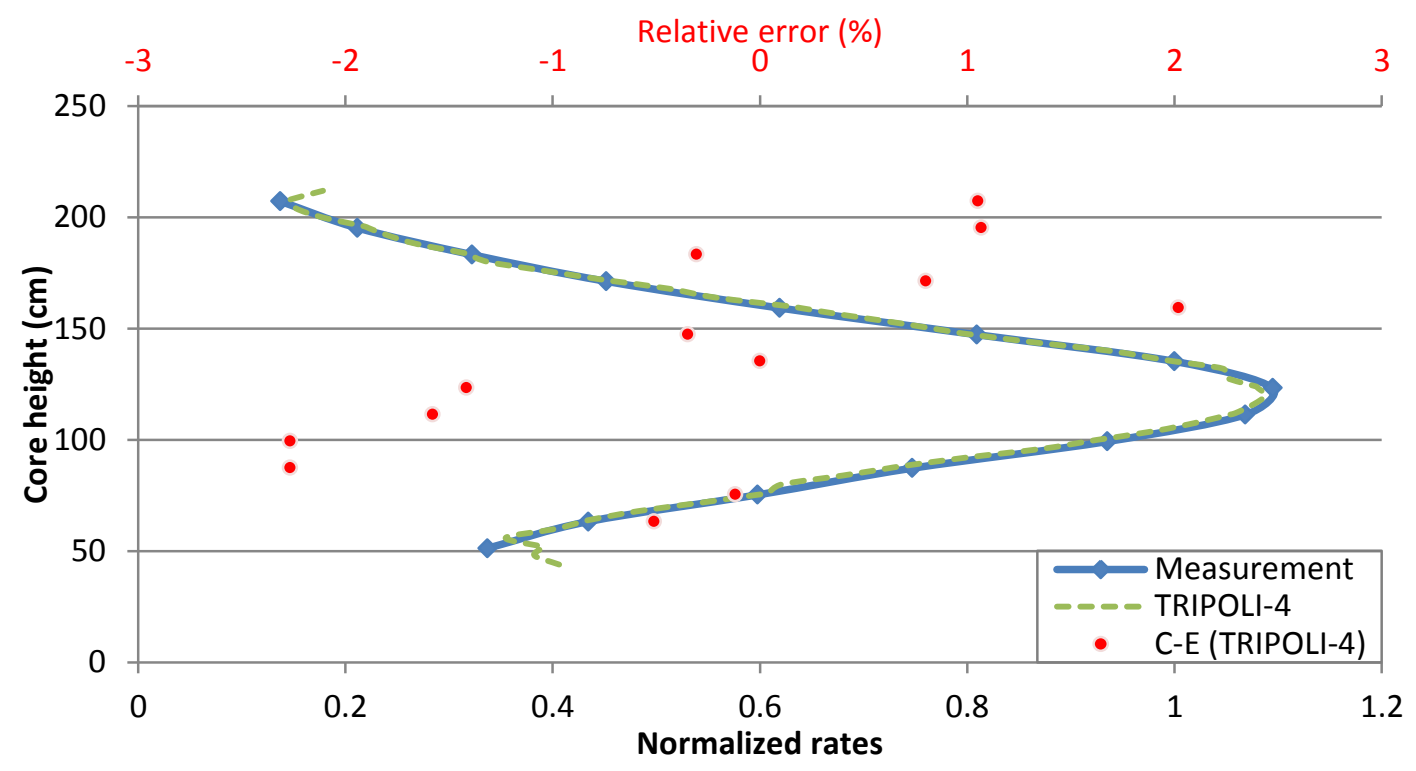

Figure 13. Measurement and TRIPOLI-4 axial ${ }^{235} \mathrm{U}$ fission rate for position 3026

The evaluations with ERANOS for the radial and axial fission rate are respectively given in Figures 15 and 16. The fission rate discrepancies between measures and ERANOS are within a $\pm 2 \%$ range. This time, the positions 3021 and 3019 present the largest discrepancies, which could be consequence of its vicinity with the dummy assembly in 3022 positon as well as for the SCP axial displacement between curtains.

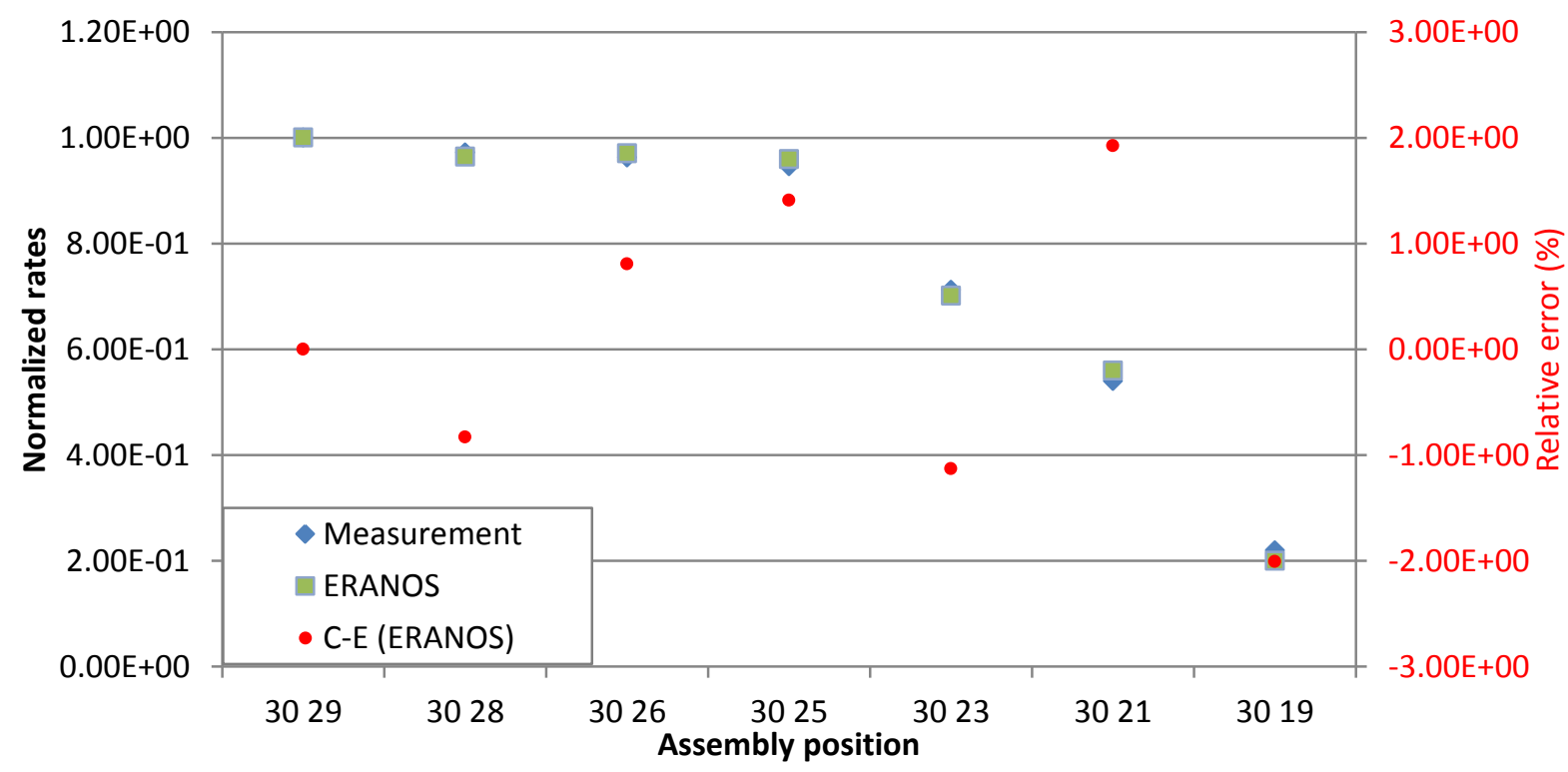

Figure 14. Measurement and ERANOS ${ }^{235} \mathrm{U}$ fission rate at mid-height of the core. 
The axial fission rate profile with ERANOS is compared to experimental measurements in Figure 16. The ERANOS evaluations presents discrepancies between $-3.7 \%$ and $1.5 \%$, however the discrepancy trend seen in T1 is a bit different; a fission rate underestimation of the core is seen along the axial direction of the assembly, except for two positions. This was also observed at the numerical verification section. A bad estimation of the rods position could be responsible of this difference of behavior with T1.

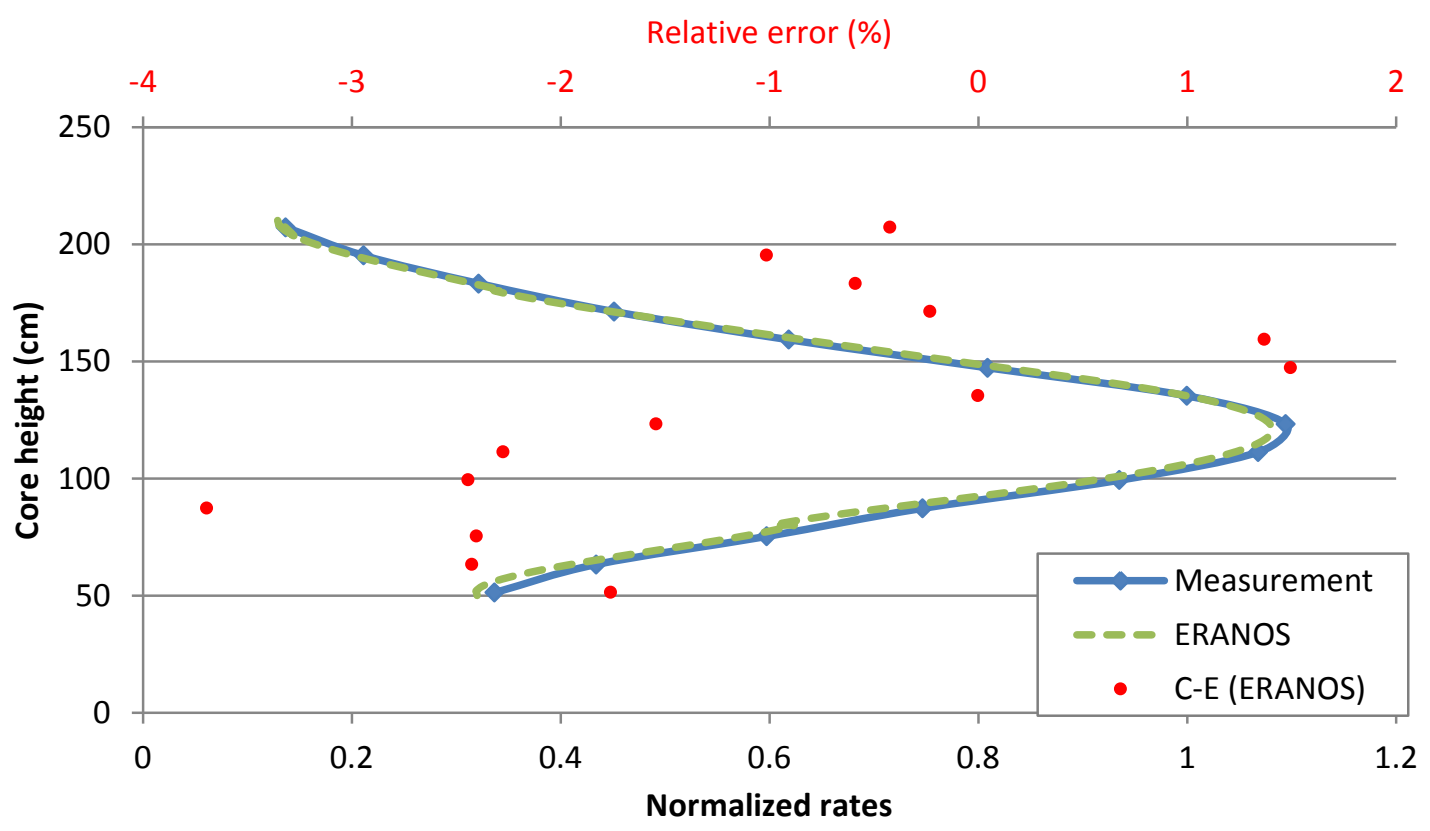

Figure 15. Measurement and ERANOS axial ${ }^{235} \mathrm{U}$ fission rate for position 3026

The evaluations for the Irradiation T2 with APOLLO-3 are shown in Figures 17 and 18, respectively for radial and axial distribution. The maximal discrepancies are identified to be in positions 3028 and 3023 , as it was also observed in the numerical verification. Discrepancies between measurements and assemblies remain between $-2 \%$ to $1.5 \%$. Even if the discrepancies are smaller, the underestimated subassemblies are the same with ERANOS and APOLLO-3: 30-28, 30-23 and 30-19.

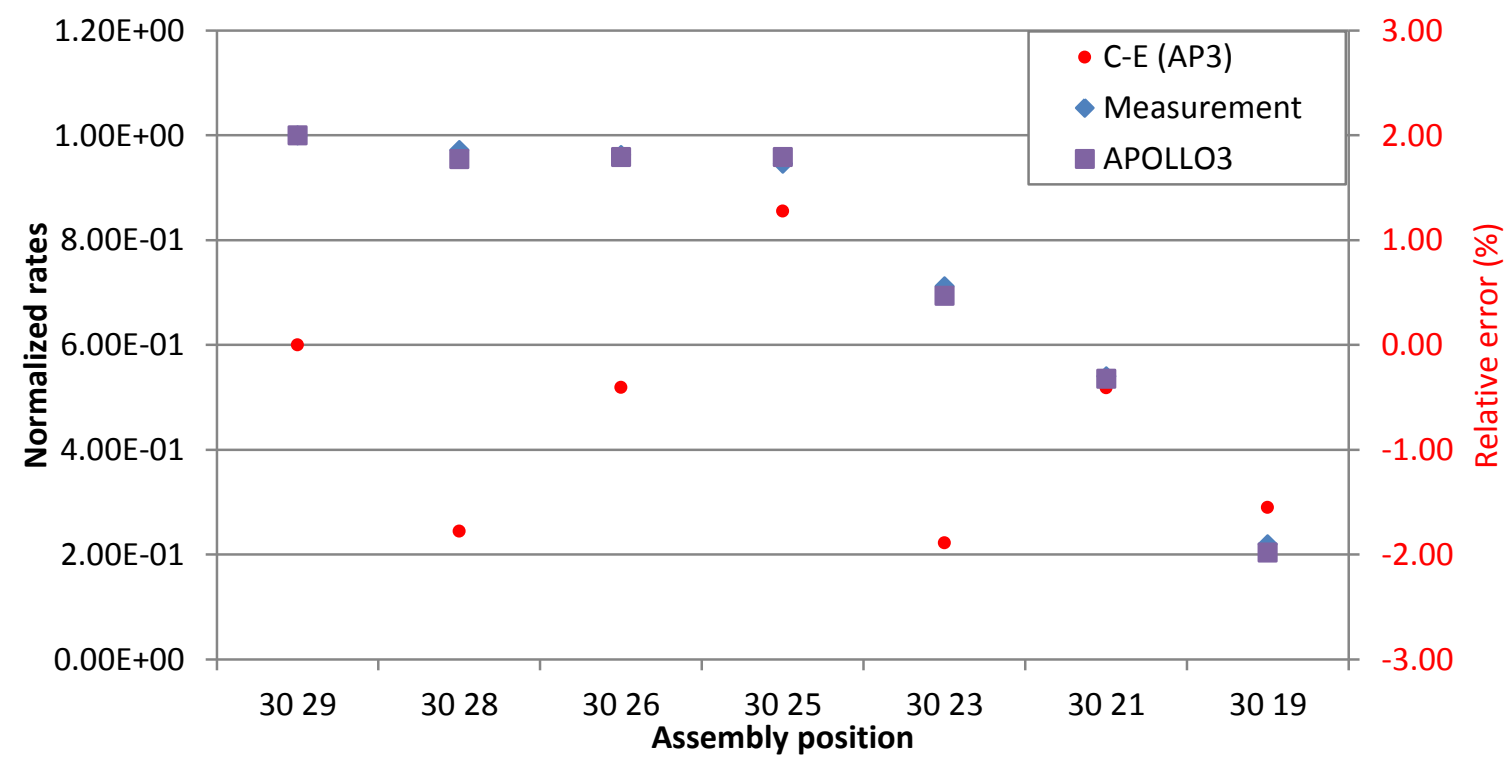

Figure 16. Measurement and APOLLO3 axial ${ }^{235} \mathrm{U}$ fission rate for position 3026 
As it is shown in Figure 18, the axial flux distribution with APOLLO-3 is consistent with measurements. The same discrepancy tendency is seen; an underestimation from the bottom to the mid-height of the core and an overestimation from the mid-height to the top of the core.

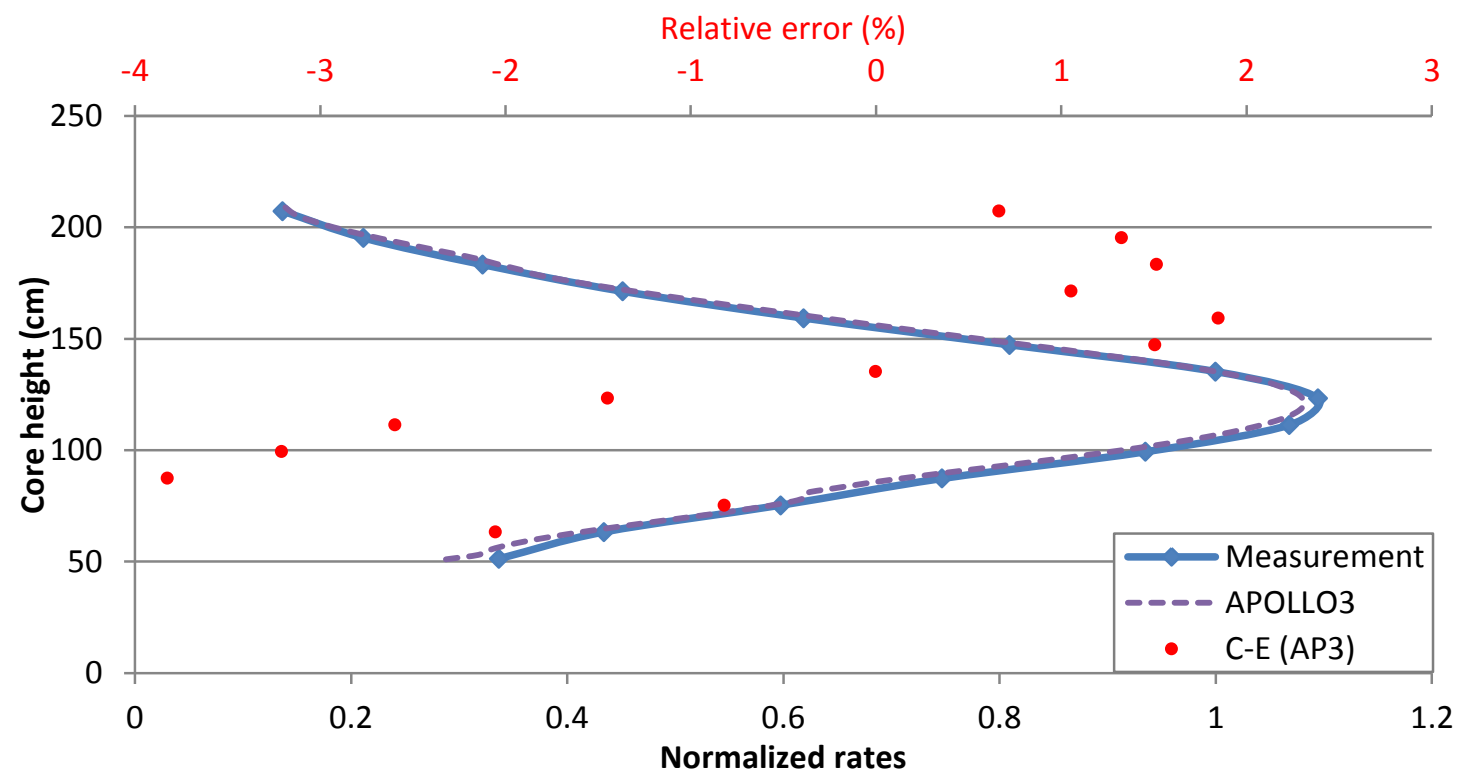

Figure 17. Measurement and APOLLO3 axial ${ }^{235} \mathrm{U}$ fission rate for position 3026

\section{Observed changes between Transversal Irradiation 1 \& 2}

The flux distribution changes between the $\mathrm{T} 1$ and the $\mathrm{T} 2$ was observed for particular subassemblies positions. The flux distribution difference between these tests was observed: a neutron flux increase at the sub-assembly positions 3028 and 3026 is identified as consequence of extracting the inner rods and inserting the outer rods of the SCP curtain, which is consistent with their positions next to an inner rod.

\section{Overall comments on the comparisons}

The TRIPOLI-4 is in very good agreement with the experiment but requires considerable computing resources. Compared to the TRIPOLI-4 evaluations, both deterministic evaluations are in good agreement with minimal discrepancies for the fission rate, either radially or axially. The use of the APOLLO-3 code presents a small improvement compared to the ERANOS evaluations, but marginal differences were found between these two codes. The use of the accurate geometrical representation of the assembly with the method of characteristics (MOC-TDT) of the APOLLO-3 code avoids some bias propagation from this stage to the core calculation. Also, the capability of the MINARET core solver to deal with sub-geometries enable a more accurate calculation of complex geometries (Guo, Martin, \& Buiron, Improvement of sodium fast reactor control rods calculations with APOLLO3 ${ }^{\circledast}$, 2018) (Faure, Archier, Vidal, \& Buiron, 2018). Hence, the APOLLO-3 is able to perform the analyses of more complex geometries as existing in future projects such as the ASTRID. 


\section{CONCLUSION}

The Superphénix remains as the largest operated SFR in the world, it legacy is of main importance for experimental programs and for the future SFRs. The flux distribution in the Superphénix core was measured during the start-up commissioning tests in two different series: the Transversal Irradiation 1 and the Transversal irradiation 2.

Stochastic tests have the ability to analyze these tests with high accuracy as it has been shown, however they are expensive in computing resources terms, reason for which deterministic codes are often used.

Hence, the analysis of the Superphénix flux distribution with the current deterministic neutronic codes is relevant since it induces limited bias. The TRIPOLI-4 is used as reference calculation for a numerical validation of the deterministic evaluations, which in this case are calculated with ERANOS and the new APOLLO-3 code. Hence, a numerical verification between a previously validated Superphénix model in TRIPOLI-4 and deterministic codes permitted to identify the bias on fission rates. In general, discrepancies between APOLLO-3 and TRIPOLI-4 and ERANOS and TRIPOLI-4 show a consistent trend which is often characterized by an underestimation from the bottom to the half height of the core, and an overestimation from the mid-height to the top of the core. Besides, the largest discrepancies were found to be at the axial fertile regions.

Despite the fact that the ERANOS code uses some approximations at different levels (such as multicell cell approach at the sub-assembly step and a full sub-assembly homogenization of the assembly at the core step, which requires a flux reconstruction), a good agreement is observed compared to the TRIPOLI-4 evaluations. This suggests that approximations done with ERANOS do not lead to large discrepancies for this kind of analyses. However, these evaluations might hide compensating errors which might not exist for more complex geometries as seen in future projects such as the ASTRID.

On the other hand, the APOLLO-3 evaluations are also in good agreement with the TRIPOLI-4 results. Given the modeling flexibility of the APOLLO-3 code, the reliability of the results might be higher for more complex designs.

An additional survey with APOLLO-3 showed that no major differences on the fission rate were obtained when switching from the JEFF 3.1.1 to JEFF 3.2 nuclear data library.

The experimental validation was then addressed by comparing each of the codes with the measurements. The TRIPOLI-4 code has very good agreement with measurements, with small discrepancies for radial and axial profiles. However, this calculation route is very expensive in computing terms; it turns to be unviable for exhaustive program analysis. The ERANOS and APOLLO3 evaluations are in good agreement with the measurements and with limited increased discrepancies on the fission rate compared to TRIPOLI4 results. Consequently, it is concluded that either deterministic code is suitable for complete analysis of the Superphénix start up tests and this whatever recent JEFF nuclear data evaluation is used.

\section{Bibliography}


Brun, E., Damian, F., Diop, C. M., Dumonteil, E., Hugot, F. X., Jouanne, C., et al. (2015). Tripoli-4 ${ }^{\circledR}$, CEA, EDF and AREVA reference Monte Carlo code. Annals of Nuclear Energy, 151-160.

Cabrillat, J. C., \& Martini, M. (1990). Power and Neutron Flux Distributions in the Core and Shielding. Nuclear Science and Engineering, 37-46.

Czernecki, S. (1998, Novembre 10). Avancées dans le calcul neutronique des réacteurs à neutrons rapides - Démostration sur le réacteur Superphénix. Thèse. Marseille, France.

Faure, B., Archier, P., Vidal, J. F., \& Buiron, L. (2018). A 2D/1D Algorithm for Effective Cross-Section Generation in Fast Reactor Neutronic Transport Calculations. Nuclear Science and Engineering, 40-51.

Flamenbaum, G., de Wouters, R., Le Bourhis, A., Newton, T., \& Vambenepe, G. (1990). Superphénix Core-Loading Strategy Using the Checkerboard Pattern. Nuclear Science and Engineering, 1117.

Flamenbaum, G., Zaetta, A., Martini, M., Michenot, M., Newton, T., \& Sztark, H. (1990). Analysis of Specific Control Rod Experiments Involving Highly Distorted Flux Distributions. Nuclear Science and Engineering , 64-68.

Garcia, E., Sciora, P., \& Rimpault, G. (2019). Evaluation of the neutronic Superphenix start-up commissioning tests with TRIPOLI4. Annals of Nuclear Energy, 366-374.

Gourdon, J., Mesnage, B., Voitellier, J., \& Suescun, M. (1990). An Overview of Superphénix Commisioning Tests. Nuclear Science and Engineering, 106, 1-10.

Guo, H., Garcia, E., Faure, B., Buiron, L., Archier, P., Sciora, P., et al. (2019). Advanced method for neutronic simulation of control rods in sodium fast reactors: Numerical and experimental validation. Annals of Nuclear Energy, 90-100.

Guo, H., Martin, G., \& Buiron, L. (2018). Improvement of sodium fast reactor control rods calculations with APOLLO3 ${ }^{\circledR}$. International Congress on Advances in Nuclear Power Plants, (pp. 1231-1240). Charlotte, North Carolina.

Mao, L., \& Zmijarevic, I. (2017). A New Tone's Method in APOLLO3 ${ }^{\circledR}$ and its Application to Fast and Thermal Reactor Calculations. Nuclear Engineering and Technology, 49(6), 1269-1286.

Rimpault, G. (1995). Algorithmic features of the ECCO cell code for treating heterogeneous fast reactors subassemblies. International Topical Meeting on Reactor Phyisics and Computations. Portland, Oregon.

Rimpault, G., Plisson, D., Tommasi, J., Jacqmin, R., Rieunier, J. M., Verrier, D., et al. (2002). THE ERANOS CODE AND DATA SYSTEM FOR FAST REACTOR NEUTRONIC ANALYSES. Physor, (pp. 1-14). Seoul.

Schneider, D., Dolci, F., Gabriel, F., Palau, J.-M., Guillo, M., \& Pothet, B. (2016). APOLLO3 ${ }^{\circledR}$ : CEA/DEN Deterministic multi-purpose code for reactor physics analysis. PHYSOR 2016, (pp. 22742285). Sun Valley ID. 
Tommasi, J., Czernecki, S., \& Rimpault, G. (2002). ANALYSIS OF SUPERPHÉNIX AND PHÉNIX NEUTRON PHYSICS EXPERIMENTS WITH THE ERANOS CODE AND DATA SYSTEM. Proc. Technical Mtg. Operational and Decommissioning Experience with Fast Reactors (pp. 1-9). Cadarache: IAEATECDOC-1405. 